\title{
Chitinase and Glucanase Activities of Antagonistic Streptomyces Spp Isolated From Fired Plots under Shifting Cultivation In Northeast India
}

\author{
Mukesh K Malviya ${ }^{1}$, Pankaj Trivedi ${ }^{2}$ and Anita Pandey ${ }^{3 *}$ \\ ${ }^{1}$ Crop Genetics Improvement and Biotechnology Lab, Guangxi Academy of Agricultural Sciences, \\ Nanning, 530007, China \\ ${ }^{2}$ Department of Bioagricultural Sciences and Pest Management, Colarado State University, C034 Plant \\ Sciences, Fort Collins - CO - 80523-1177 \\ ${ }^{*}$ Biotechnological Applications, G.B. Pant National Institute of Himalayan Environment and Sustainable \\ Development, Kosi-Katarmal, Almora, 263643 Uttarakhand, India
}

Received: 10 November, 2017; Accepted: 19 January, 2018; Published: 31 May 2018

*Corresponding author: Anita Pandey, Biotechnological Applications, G. B. Pant National Institute of Himalayan Environment and Sustainable Development, Kosi-Katarmal, Almora, 263643 Uttarakhand, India; E-mail: anita@gbpihed.nic.in

\begin{abstract}
Antagonistic Streptomyces spp (Streptomyces sp NEA55 and Streptomyces cavourensis NEA5), isolated from fired plots under shifting cultivation in northeast India, are studied for their chitinase and glucanase activities. The species showed strong antagonism against test fungi (Rhizoctonia solani and Cladosporium sp.) in plate assays. Maximum \% inhibition was observed due to the effect of diffusible compounds produced by these species. Streptomyces sp. NEA55 showed $54.83 \%$ inhibition against $R$. solani while $S$. cavourensis NEA5 showed up to $50.00 \%$ inhibition against Cladosporium sp. The inhibitory effect of volatile compounds by Streptomyces sp NEA55 was recorded up to $50.7 \%$ against $R$. solani and $37.50 \%$ against Cladosporium sp. While $S$. cavourensis NEA5 showed $49.23 \%$ inhibition against R. solani and $34.37 \%$ inhibition against Cladosporium sp. S. cavourensis NEA5 and Streptomyces sp. NEA55 produced $0.138 \pm 0.006 \mu \mathrm{g} / \mathrm{ml}$ and $0.15 \pm 0.004 \mu \mathrm{g} / \mathrm{ml}$ chitinase, $0.22 \pm 0.001 \mu \mathrm{g} / \mathrm{ml}$ and $0.25 \pm 0.002 \mu \mathrm{g} / \mathrm{ml} \beta 1,3$ glucanase, respectively. Both the species showed maximum chitinase activity at $\mathrm{pH} 6$ and temperature $50 \stackrel{\circ}{\circ}$, while minimum enzyme activity was observed at $\mathrm{pH} 10$ and temperature $20^{\circ} \mathrm{C}$. Both the species showed glucanase activity maximum at $\mathrm{pH} 7$ and temperature $40{ }^{\circ} \mathrm{C}$ and minimum activity at pH 10 and temperature $20{ }^{\circ} \mathrm{C}$. Both the species hydrolyzed glycol-chitin as a substrate in denaturing conditions showing variable amount of different isoforms. This study demonstrates that the antagonistic species of Streptomyces survive the fire operations under shifting cultivation.
\end{abstract}

Keywords: Streptomyces; Antagonism; Chitinase; Glucanase; Shifting cultivation

\section{Introduction}

Actinobacteria are most widely distributed and distinct group of microorganisms in nature. Actinobacteria, Streptomyces species in particular, has been a broadly exploited group of microorganisms for the production of important secondary metabolites and enzymes in the field of medicine and agriculture
$[1,2]$. Streptomyces are well known as antifungal biocontrol agents that inhibit several plant pathogenic fungi [3]. The antagonistic activity of Streptomyces to fungal pathogens is usually related to the production of antifungal compounds and extracellular hydrolytic enzymes [4, 5]. Many species of Streptomyces are well known as antifungal biocontrol agents that inhibit several plant pathogenic fungi e.g., Phytophthora capsici Sclerotinia rolfsii, Fusarium sporotrichiodes, Rhizoctonia solani and Sclerotium rolfsii, Alternaria alternata and Phomopsis archeri [6-9]. Furthermore, Streptomyces produce bioactive compounds such as antimicrobial, antiparasitic and immune-suppressing compounds via secondary metabolism. Streptomycetes have been found in beneficial associations with plants where they improve plant growth and protect against pests; this has attracted the attention of researchers worldwide [10].

Chitinase and $\beta$-1,3-glucanase are considered to be important hydrolytic enzymes in the lysis of fungal cell walls [11]. Chitinolytic enzymes have been identified in several Streptomyces spp. including Streptomyces sp. M-20, S. venezuelae $\mathrm{P} 10$, and S. anulatus CS242 [12-14]. Glucanase has been known to be produced by several microorganisms and playing important role in biocontrol [15]. Several Streptomyces have been studied for antifungal properties along with the production of glucanase, some of the examples are Streptomyces sp. S27 and Streptomyces sp. Mo $[16,17]$. Shifting cultivation, refers to 'slash and burn', is a predominant form of agricultural practice in hills of northeast India. The microbiological aspects, basically survival of bacterial, fungal and actinobacterial communities after fire events have been studied in recent times [18-20]. The focus of present study is on the antagonistic potential of two Streptomyces species that were isolated after the fire events. These species have been studied with respect to production of diffusible and volatile compounds 
against test fungi along with the chitinase and $\beta$-1, 3 -glucanase activities. In addition, both the species are also studied with hydrolyzed glycol-chitin as a substrate in denaturing conditions.

\section{Material and Methods}

\section{Study site and isolation of actinobacteria}

Actinobacteria were isolated from the soil samples that were collected after the completion of fire events in Papumpare District, Itanagar, Arunachal Pradesh under shifting cultivation. The details of the study sites have been described in Pandey et al. [18]. Among the two actinobacterial isolates used in the present study, isolate no. NEA5 showed maximum similarity with Streptomyces cavourensis NR_043851 and NEA55 with Streptomyces sp. YIM8 AF389344 [19]. The test fungi (Rhizoctonia solani and Cladosporium sp.) were also originally isolated from shifting cultivation site [20].

\section{Scanning electron microscopy}

In order to see the deep morphological pattern (substrate and aerial mycelia) of Streptomyces spp. scanning electron microscopy was performed. Glutaraldehyde (2.5\%) was added to the culture and then centrifuged. After centrifugation, washing was given with phosphate buffer saline (PBS) twice and centrifuged. The sample was dehydrated with CPD (Critical dry point), and then the samples were coated with gold by auto fine coater (JFC-1600). After coating, the sample was viewed under scanning electron microscope (JSM-6610LV).

Dual culture technique for determination of the production of diffusible antifungal compounds

To test the ability of the Streptomyces spp. to inhibit the phytopathogens, the test fungal culture and Streptomyces sp. was spot inoculated off-center on each potato carrot agar (PCA) plate. After 7 days of incubation at $28 \stackrel{\circ}{\circ}$, the zone of inhibition was measured. Per cent growth inhibition was calculated using the following formula: $(\mathrm{R} 1-\mathrm{R} 2) / \mathrm{R} 1 \times 100$ (where R1 represents the radius of the test fungus in the direction with no bacterial colony and $\mathrm{R} 2$ is the radius of the fungal colony in the direction of the bacterial colony) as described in Trivedi et al. [21].

Sealed double Petri plate technique for determination of the production of volatile antifungal compounds

Each Streptomyces sp. was streaked on Petri plate containing PCA and a $6.0 \mathrm{~mm}$ disc of 4 days old culture of the test fungus was placed in the middle of another PCA plate. The lid of both the plates were replaced with the plates of same diameter, placed face to face, and sealed by parafilm, preventing any physical contact between the pathogen and the Streptomyces sp. Petri plates were incubated at $28{ }^{\circ} \mathrm{C}$ for 7 days and growth of the pathogen was measured and compared to control developed in the absence of the antagonist (mocked inoculation with a $6.0 \mathrm{~mm}$ disc of PCA). Results were expressed as means of per cent inhibition of the growth of each fungus in the presence or absence of the antagonistic Streptomyces sp. Per cent growth inhibition was calculated by the following formula: (R1-R2)/R1 × 100, where R1 represents the diameter of the test fungus on control plate and R2 is the diameter of the growth on inoculated plate.

\section{Quantitative estimation of production of chitinase and glucanase on different temperature and $\mathrm{pH}$}

Quantification of chitinase and glucanase has been done following prescribed procedures [22]. The Streptomyces species were cultured at $28{ }^{\circ} \mathrm{C}$ for 5 days on a rotary shaker in 250.0 $\mathrm{ml}$ of chitin peptone medium for chitinase production and peptone medium containing laminarin $(0.2 \%)$ (from Laminaria digitata, Sigma) for glucanase production [23]. The cultures were centrifuged at $12,000 \mathrm{~g}$ for $20 \mathrm{~min}$ at $4{ }^{\circ} \mathrm{C}$ and the supernatants were used as enzyme source. The reaction mixture contained 0.25 $\mathrm{ml}$ of enzyme solution, $0.3 \mathrm{ml}$ of $\mathrm{pH}$ buffer (1.0 M citrate buffer $\mathrm{pH} 5$, phosphate buffer $\mathrm{pH} 6$ to 8 , and glycine buffer $\mathrm{pH} 9$ ). The reaction mixtures were incubated at different temperatures $(20$, $30,40,50$ and $60^{\circ} \mathrm{C}$ ) for $4 \mathrm{~h}$ in a water bath. One unit of chitinase was determined as $1 \mu \mathrm{mol}$ of $\mathrm{N}$ acetyl glucosamine (GlcNAc) released min-1 and $\beta$-1, 3-glucanase activity was determined as 1 $\mu \mathrm{mol}$ of glucose released min-1. Protein content was determined as described by Lowry method [24].

\section{SDS-PAGE analysis for chitinase}

Streptomyces spp. was grown as shake culture in chitinpeptone medium at $28{ }^{\circ} \mathrm{C}$ for 7 days. The supernatant was centrifuged at $12000 \mathrm{~g}$ for $20 \mathrm{~min}$ at $4 \stackrel{\circ}{\circ} \mathrm{C}$ and filtered through 0.22 $\mu \mathrm{l}$ sterile filter (Millipore) and collected in conical flask. Protein content was analyzed by SDS-PAGE [25]. Polyacrylamide slab gel consisted of $4 \%$ stacking gel and $10 \%$ separating gel containing $0.01 \%$ glycol-chitin. Electrophoresis was carried out at a constant voltage of $65 \mathrm{~V}$; gel was stained with coomassie brilliant blue R-250 and analyzed under gel documentation system (Alpha Imager 2200). Glycol chitin was prepared as described by Trudel and Asselin [26].

\section{Results and Discussion}

The scanning electron microscopy of both the species is presented in Figure: $1 \mathrm{~A}$ and Figure: 1B. Scanning electron microscopy revealed definite structures of mycelium and spores of both the Streptomyces spp. Two of the isolates that were used for detailed studies based on their antagonistic properties were subjected to scanning electron microscopy. The scanning electron microscopy has been referred to provide perfect characterization of streptomycetes [27]. The effect of diffusible compounds produced by the Streptomyces spp., evaluated in terms of reduction in radial growth of two test fungi viz. Rhizoctonia solani and Cladosporium sp., following 7 days of incubation at $28{ }^{\circ} \mathrm{C}$, are presented in Figure: 2 \& Table 1. The results showed that volatile compounds produced by Streptomyces spp. were inhibitory to the growth of the test fungi, viz. $R$. solani and Cladosporium sp. Inhibition (\%) in fungal growth by Streptomyces species is presented in Table 1. Microscopic observations revealed that the diffusible as well as volatile compounds produced by 


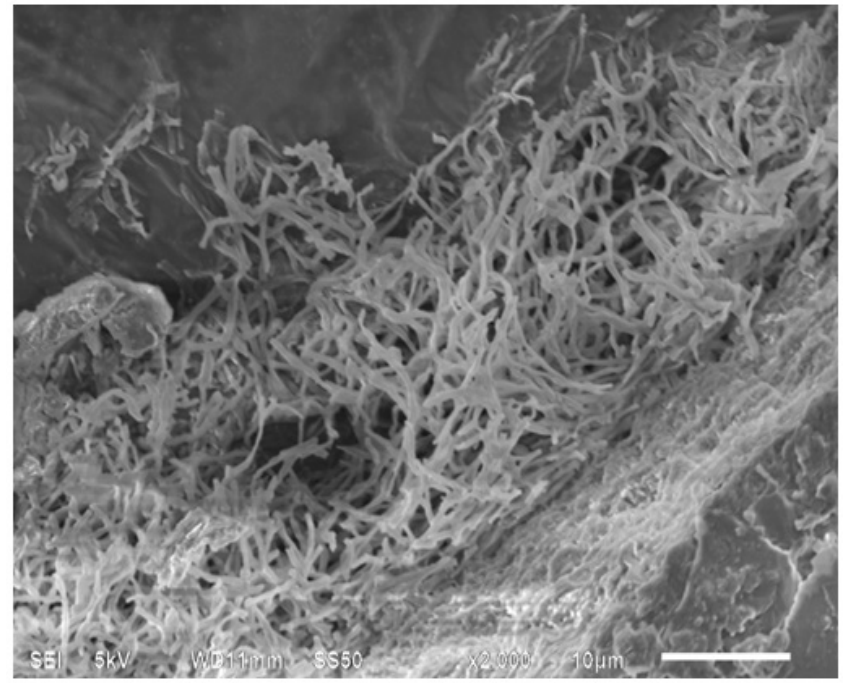

Figure 1A: Scanning electron micrograph of Streptomyces cavourensis NEA5

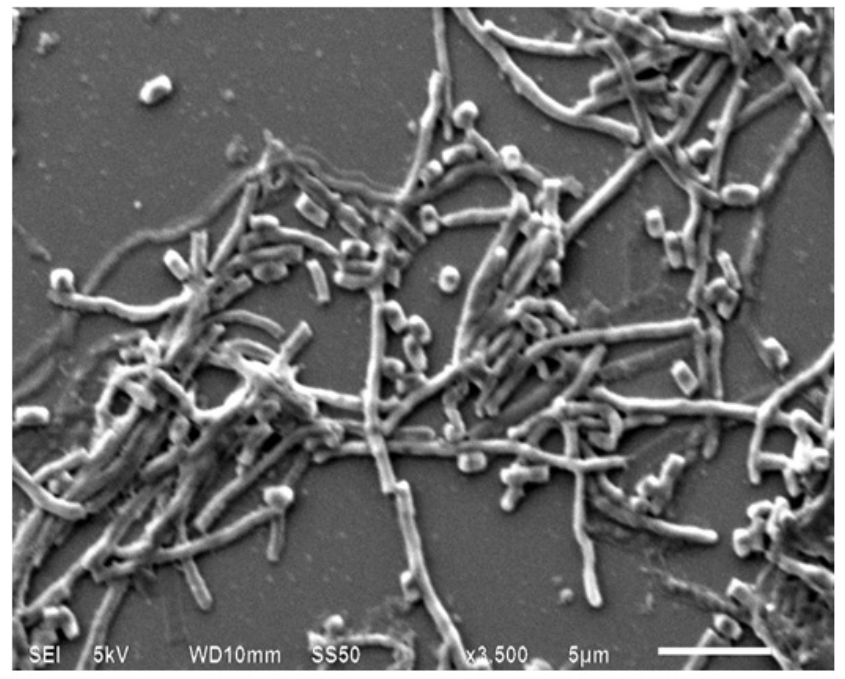

Figure 1B: Scanning electron micrograph of Streptomyces sp. NEA55
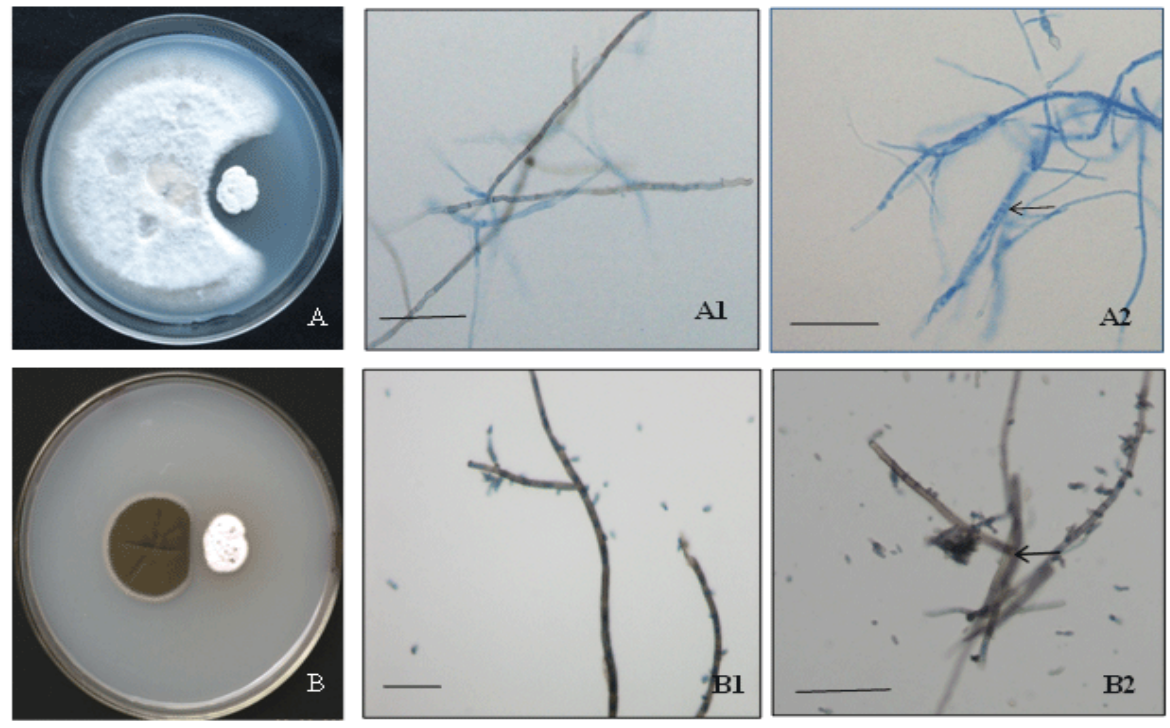

Figure 2: Production of antifungal compounds by Streptomyces cavourensis NEA5 \& Streptomyces sp. NEA55 (A\&B) respectively: Inhibition of R. solani and Cladosporium sp. due to diffusible compounds produced. Morphological deformities: (A1\&B1) Normal structures of R. soloni and Cladosporium sp. (A2\&B2) deformed structures of respective fungus. (Bar $=5 \mu \mathrm{m})$

Table 1: In vitro percent inhibitory effect of diffusible and volatile metabolites of Streptomyces species on growth of test fungi

\begin{tabular}{|c|c|c|c|c|}
\hline \multirow{2}{*}{ Pathogenic test fungi } & \multicolumn{3}{|c|}{ \% Inhibition in fungal growth by Streptomyces spp. after 7 days of incubation } \\
\cline { 2 - 5 } & \multicolumn{2}{|c|}{ Streptomyces cavourensis NEA5 } & \multicolumn{2}{|c|}{ Streptomyces sp NEA55 } \\
\hline Rhizoctonia solani & 51.61 & 49.23 & 54.83 & 50.07 \\
\hline Cladosporium sp. & 50 & 34.37 & 47.7 & 37.5 \\
\hline
\end{tabular}

Citation: Malviya KM, Trivedi P, Pandey A (2018) Chitinase and Glucanase Activities of Antagonistic Streptomyces Spp Isolated From Fired Plots under Shifting Cultivation In Northeast India. J Adv Res Biotech 3(1):1-7. DOI: 10.15226/2475-4714/3/1/00130 
Table 2: Comparative account of structures of normal and antagonized pathogen

\begin{tabular}{|c|c|c|c|}
\hline \multirow{2}{*}{ Test fungi } & Structure & Normal & Antagonized \\
\hline \multirow{2}{*}{ Rhizoctonia } & Mycelium & Somatic and fertile hypha well distinguished & Irregular \\
\hline \multirow{2}{*}{ Solani } & Somatic hypha & Septate, dia. $2.5-3.5 \mu \mathrm{m}$ & Irregular \\
\cline { 2 - 4 } & Fertile hypha & Septate and dark in colour, dia. $3.0-4.5 \mu \mathrm{m}$ & Irregular septate, dia $3.0-7.5 \mu \mathrm{m}$ \\
\cline { 2 - 4 } & Hyphal wall & Present & Lysed \\
\hline \multirow{2}{*}{ Cladosporium sp. } & Mycelium & Somatic hypha septate, dia. $2-3.5 \mu \mathrm{m}$ & Somatic hypha septate, dia. $2-5 \mu \mathrm{m}$ \\
\cline { 2 - 4 } & Conidia & Curved or straight width 2.0-2.5 $\mu \mathrm{m}$ & Irregular width 2-4 $\mu \mathrm{m}$ \\
\hline
\end{tabular}

Streptomyces species induced morphological abnormalities in the fungal structures (Table 2). Deformation was observed in mycelial, hyphal or conidial structures. The longitudinal septae completely disappeared and the conidia became thick walled and spherical or irregular in shape. Lysis of fungal hyhae and vacuolization as well as granulation in mycelium was observed in $R$. solani. Size of the somatic and fertile hypha of $R$. solani increased due to the antagonistic effect of actinobacteria. Due to the antifungal activity of Streptomyces sp., hyphal wall of $R$. solani was completely lysed. In case of Cladosporium sp., size of mycelium and conidia increased with irregular shape of conidia. The inhibition of growth of the test pathogenic fungi continued to increase with increasing incubation time. A clear inhibitory area and dense sporulation ring was observed near the growth of the isolate which antagonized respective test fungi. No physical contact was observed between the Streptomyces species and the test fungi that were observed to be antagonized. Moreover, the formation of the inhibitory halo suggested the presence of fungicidal metabolites secreted by Streptomyces. Similar observations have been reported by Aghigni et al. [28] from a number of actinobacterial isolates from Iranian soil. These isolates formed inhibition zones in dual culture based assays inhibiting the growth of Alternaria solani, A. alternata, Fusarium solani, Phytophthora megaperma, Verticillium dahlia and Saccharomyces cerevisiae. The antifungal potential of actinobacteria against Colletotrichum gloeosporioides and Sclerotium rolfsii was assessed by dual culture technique [10]. Al-Askar et al. [29] reported that Streptomyces spororaveus RDS28 produces antifungal compounds against some phytopathogenic fungi, viz., Rhizoctonia solani, Fusarium solani, F. verticillioides, Alternaria alternata and Botrytis cinerea. There was a change in colour of the test fungi in inoculated plates, indicative of the inhibitory effect of volatile compounds. The test fungi, inhibited by the Streptomyces, under present study exhibited morphological abnormalities due to the production of diffusible and volatile antifungal compounds. Abnormal hyphal swelling, degradation and lysis of mycelia were observed by Joo [6] when Phtophthora capsici was grown with the high or low molecular fraction of Streptomyces halstedii AJ-7.

Quantitative estimation of production of chitinase and $\beta 1$, 3 glucanase activities is presented in Figure 3 (A\&B) showing maximum activity of chitinase and glucanase. Effect of different
$\mathrm{pH}$ and temperature on chitinase activity of both the species is presented in Figure 4 (A\&B). Both the species showed maximum activity of chitinase at $\mathrm{pH} 6$ and temperature $50 \stackrel{\circ}{\circ}$, while minimum enzyme activity was observed at $\mathrm{pH} 10$ and temperature $20 \stackrel{\circ}{\circ}$. In case of glucanase activity both the species showed maximum enzyme activity at $\mathrm{pH} 7$ and temperature 40 ${ }^{\circ} \mathrm{C}$ and minimum activity at $\mathrm{pH} 10$ and temperature $20{ }^{\circ} \mathrm{C}$ (Figure $5 A \& B)$. Kim et al. [12] reported maximum activity of chitinase

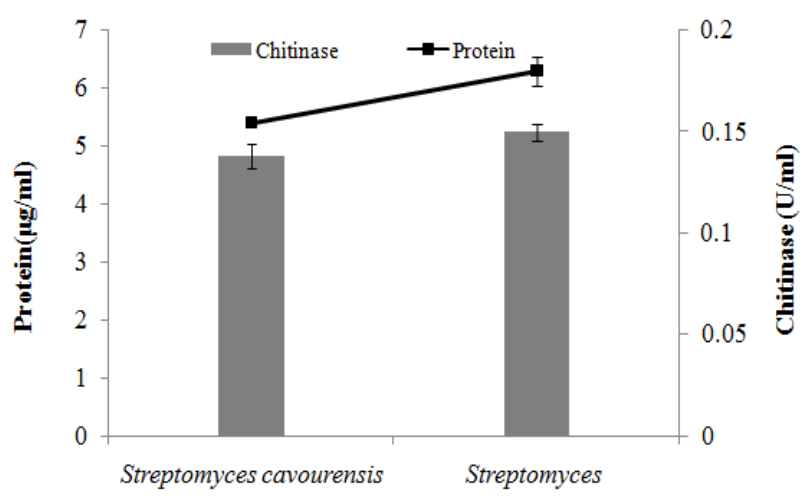

Figure 3A: Quantitative estimation of chitinase activity

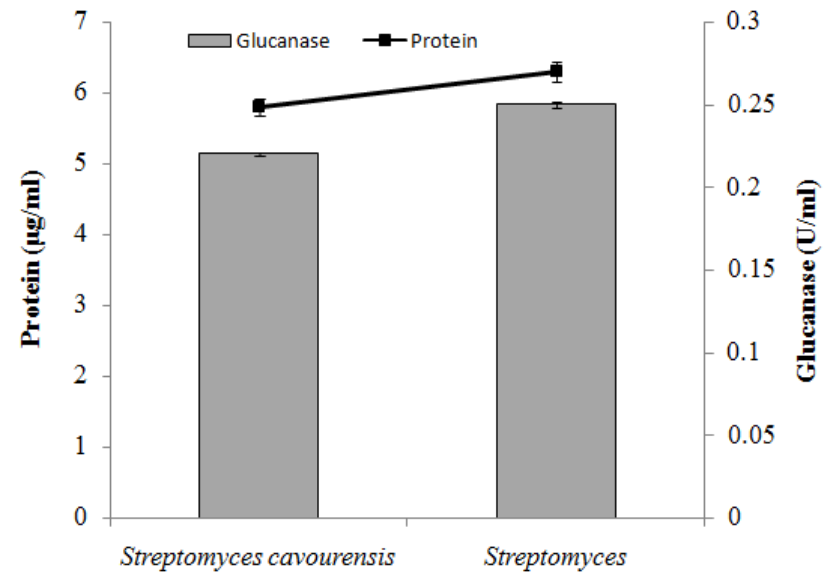

Figure 3B: Quantitative estimation of glucanase activity 

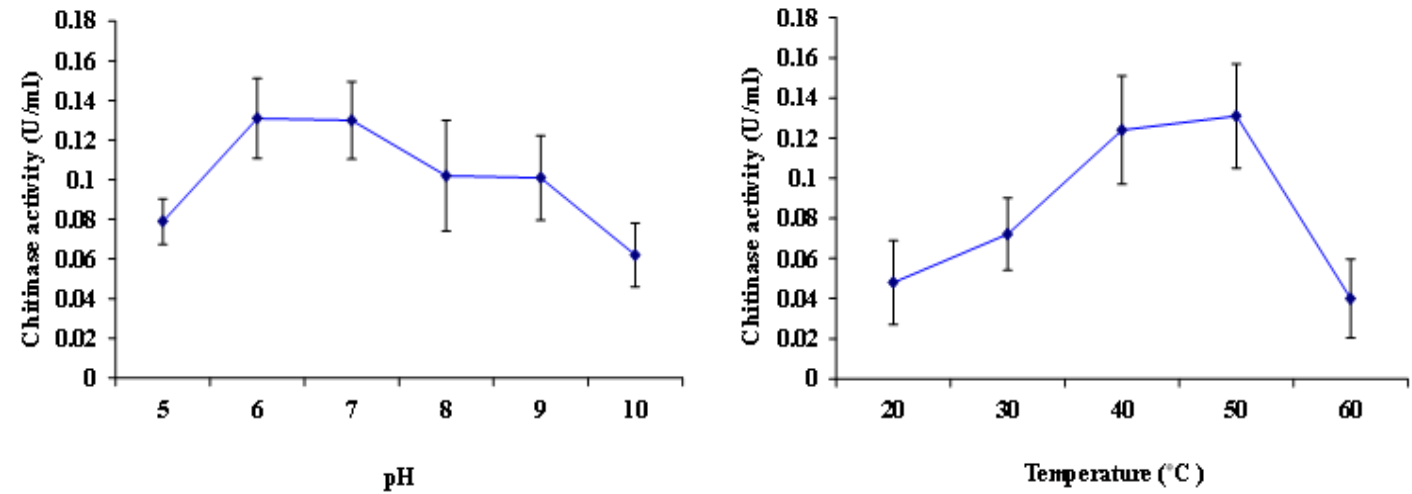

Figure 4A: Chitinase activity of Streptomyces cavourensis NEA5 at different $\mathrm{pH} \&$ temperature
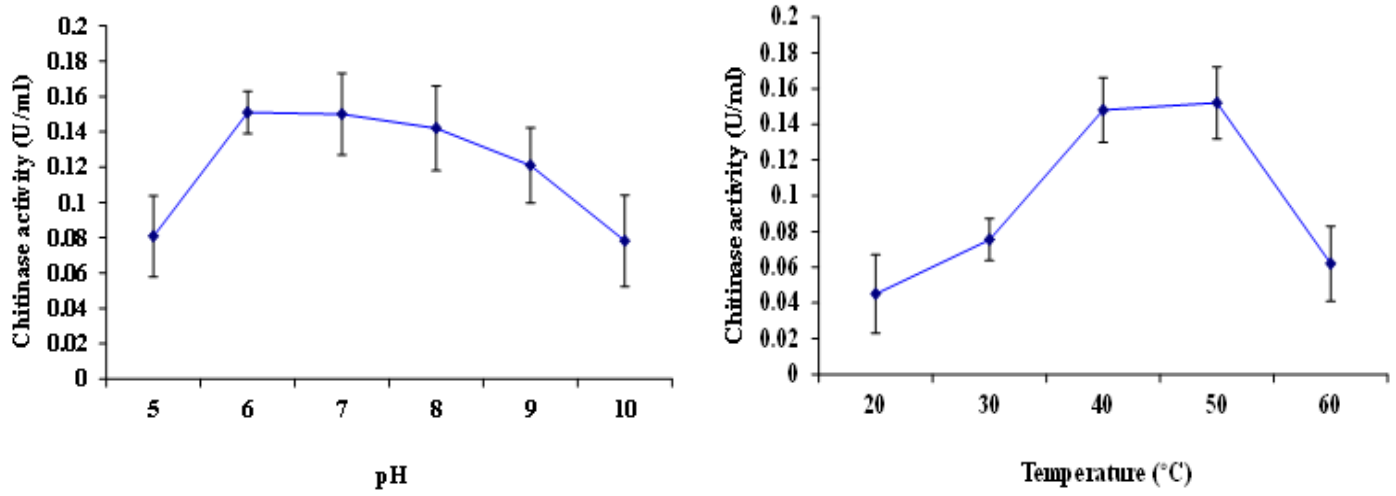

Figure 4B: Chitinase activity of Streptomyces sp NEA55 at different pH \& temperature
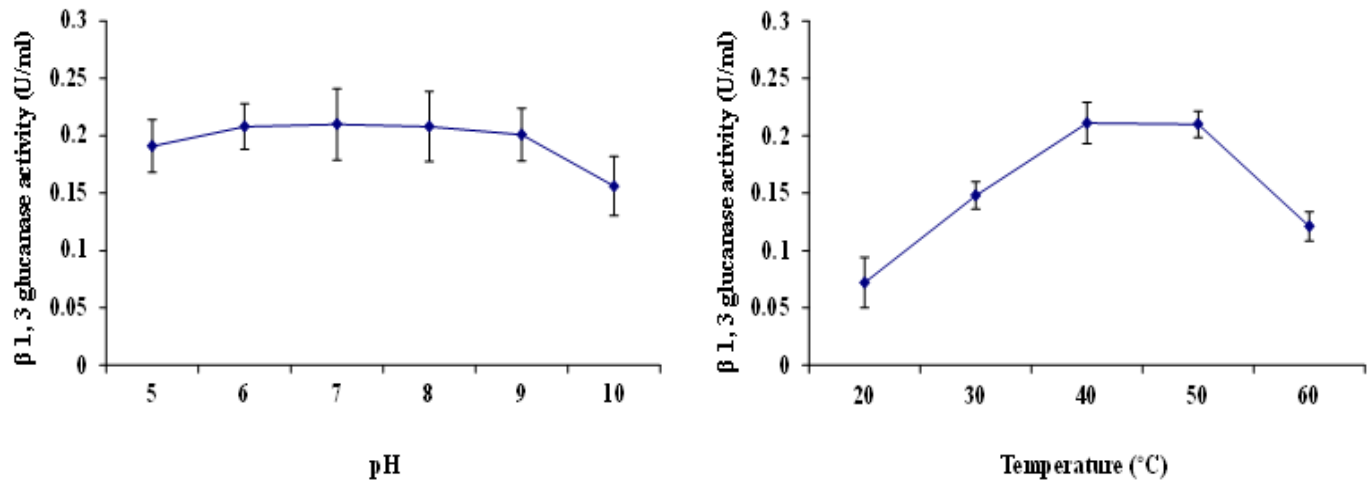

Figure 5A: Glucanase activity of Streptomyces cavourensis NEA5 at different $\mathrm{pH} \&$ temperature

between $\mathrm{pH} 5.0$ to 6.0 and it was relatively stable at $\mathrm{pH} 4.0$ to 8.0 when kept at $4{ }^{\circ} \mathrm{C}$. Beyond this $\mathrm{pH}$ range there was a rapid loss in the activity. Glucanase activity of the two isolates was found maximum at $\mathrm{pH} 7$ and temperature $40{ }^{\circ} \mathrm{C}$. Highest activity was found between $\mathrm{pH} 5$ to 8 and temperature 30 to $50^{\circ} \mathrm{C}$, in previous studies. The optimum activity for short term incubation is often seen at temperature in the range of 30 to $50{ }^{\circ} \mathrm{C}$, while many fungal glucanases appear stable between 50 to $60^{\circ} \mathrm{C}$ [30].
SDS-PAGE exhibited the chitinase activity of the two Streptomyces species (NEA5 \& NEA55). Streptomyces species hydrolyzed glycol-chitin as a substrate in denaturing conditions. Species showing variable amount of different isoforms with molecular weights between 31 to $40 \mathrm{kDa}$ are presented in Figure 6. Majority of bacterial chitinases has been reported to be in the range of 20 to $60 \mathrm{kDa}$. Chitinases from various Streptomyces were found to possess molecular weights as $20 \mathrm{kDa}$ from Streptomyces 

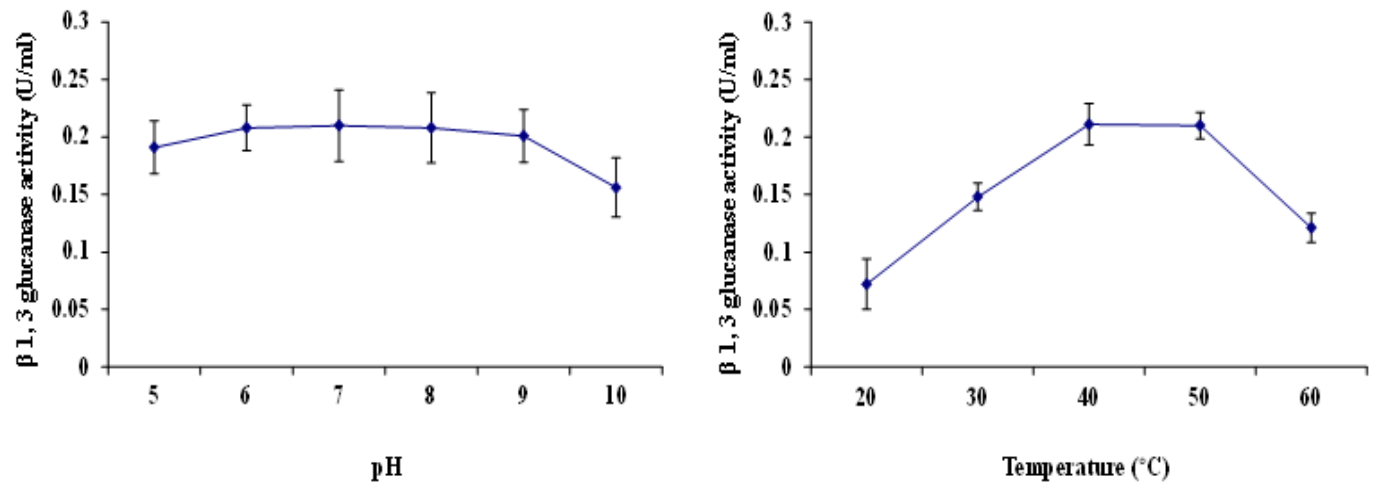

Figure 5B: Glucanase activity of Streptomyces sp NEA55 at different pH \& temperature

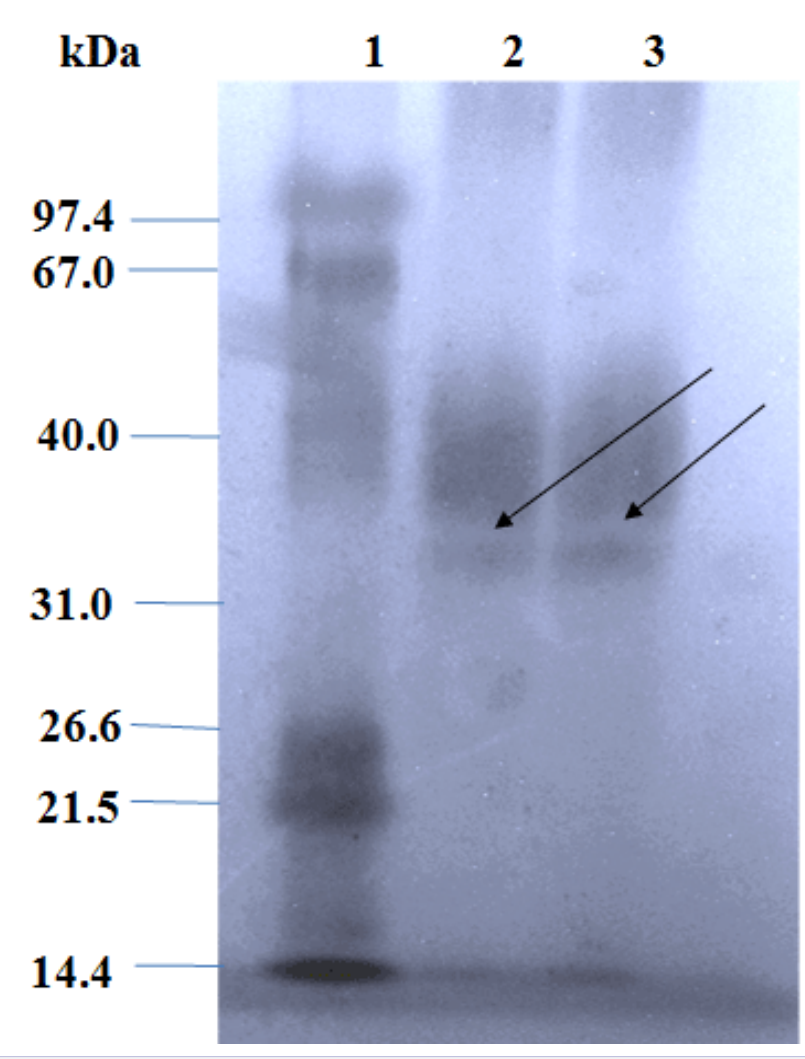

Figure 6: Detection of chitinase activity after SDS-PAGE using glycol chitin as substrate, lane 1 (Molecular weight markers), lane 2 and 3 sample Streptomyces cavourensis NEA5 and Streptomyces sp NEA55, respectively

sp. M-20 [13] and some strains of Streptomyces varying from approximately $25 \mathrm{kDa}$ to $200 \mathrm{kDa}$ [31].

The aim of this work is to prove the potential of Streptomyces species to survive the fire operations retaining their potential to reduce or eliminate the plant pathogenic fungi. Such robust isolates may prove to be the potential biocontrol agents for field applications. Further studies are needed in order to determinate the nature of Streptomyces species metabolites and their mechanism of action.

\section{Acknowledgment}

Director (GBPNIHESD) for extending the facilities and Ministry of Environment, Forest and Climate Change, Govt. of India, New Delhi for financial support.

\section{References}

1. Kumar D, Gupta RK. Biocontrol of wood rotting fungi. Ind J Biotechnol. 2006; 5:20-25.

2. Narayana KJP, Vijayalakshmi M. Chitinase production by streptomyces sp. anu 6277. Braz J Microbiol. 2009; 40(4): 725-733.

3. El-Tarabily KA, Soliman MH, Nassar AH, Al-Hassani HA, Sivasithamparam K. Biocontrol of sclerotinia minor using a chitinolytic bacterium and actinomycetes. Plant Pathol. 2000; 49: 573-583.

4. Fourati-Ben Fguira L, Fotso S, Ben Ameur-Mehdi R, Mellouli L, Laatsch H. Purification and structure elucidation of antifungal and antibacterial activities of newly isolated Streptomyces sp. strain US80. Res Microbiol. 2005; 156(3): 341-347.

5. Trejo-Estrada SR, Sepulveda IR, Crawford DL. In vitro and in vivo antagonism of Streptomyces violaceusniger YCED9 against fungal pathogens of turfgrass. World J Microbiol Biotechnol. 1998;14(6):865-872.

6. Joo GJ. Production of an anti-fungal substance for biological control of Phytopthora capsici causing blight in red-peppers by Streptomyces halstedii. Biotechnol Lett. 2005;27(3):201-205.

7. Errakhi R, Bouteau F, Lebrihi A, Barakate M. Evidences of biological control capacities of Streptomyces spp. against Sclerotium rolfsii responsible for damping-off disease in sugar beet (Beta vulgaris L.). World J Microbiol Biotechnol. 2007;23(11):1503-1509.

8. Rugthaworn P, Uraiwan Dilokkunanant, Sangchote S, Piadang N, Kitpreechavanich V. Search and improvement of actinomycete strains for biological control of plant pathogens. Kasetsart J (Nat Sci). 2007;41:248-254.

9. Malviya MK, Pandey A, Trivedi P, Gupta G, Kumar B. Chitinolytic activity of cold tolerant antagonistic species of streptomyces isolated from glacial sites of Indian Himalaya. Curr Microbiol. 2009;59(5):502-508. doi: 10.1007/s00284-009-9466-z

10. Sousa JAJ, Olivares FL. Plant growth promotion by streptomycetes: ecophysiology, mechanisms and applications. Chem Biol Technol Agric. 2016; 3:24. 
11. Prapagdee B, Kuekulvong C, Mongkolsuk S. Antifungal potential of extracellular metabolites produced by Streptomyces hygroscopicus against phytopathogenic fungi. Int J Biol Sci. 2008;4(5):330-337.

12.Kim KJ, Yang YJ, Kim JG. Purification and characterization of chitinase from Streptomyces sp. M-20. J Biochem Mole Biol. 2003;36(2):185-189.

13. Mukherjee G, Sen SK. Purification, characterization, and antifungal activity of chitinase from Streptomyces venezuelae P10. Curr Microbiol. 2006;53(4):265-269.

14. Mander P, Cho SS, Choi YH, Panthi S, Choi YS, Kim HM, Yoo JC et al Purification and characterization of chitinase showing antifungal and biodegradation properties obtained from Streptomyces anulatus CS242. Arch Pharm Res. 2016;39(7):878-886. doi: 10.1007/s12272016-0747-3

15.El-Katatny MH, Gudelj M, Robra KH, Elnaghy MA, Gubitz GM. Characterization of a chitinase and an endo- $\beta$-1,3-glucanase from Trichoderma harzianum Rifai T24 involved in control of the phytopathogen Sclerotium rolfsii. Appl Microbiol Biotechnol. 2001; 56(1-2):137-143.

16. Shi P, Yao G, Li N, Luo H, Bai Y, Wang Y, Yao Bin et al. Cloning, characterization, and antifungal activity of an endo-1,3- $\beta-\mathrm{D}$ : -glucanase from Streptomyces sp. S27. Appl Microbiol Biotechnol. 2010;85(5):1483-1490. doi: 10.1007/s00253-009-2187-1

17. Kurakake M, Yamanouchi Y, Kinohara K, Moriyama S. Enzymatic properties of $\beta$-1,3-glucanase from Streptomyces sp Mo. J Food Sci. 2013;78(4):502-506. doi: 10.1111/1750-3841.12076

18. Pandey A, Chaudhry S, Sharma A, Choudhary VS, Malviya MK Chamoli S, Rinu K, Trivedi P, Palni LM et al. Recovery of Bacillus and Pseudomonas spp from the 'Fired Plots' under Shifting Cultivation in Northeast India. Curr Microbiol. 2011; 62(1): 273-280. doi: 10.1007/ s00284-010-9702-6

19. Malviya MK, Pandey A, Sharma A, Tiwari SC. Characterization and identification of actinomycetes isolated from 'fired plots' under shifting cultivation in northeast Himalaya, India. Ann Microbiol. 2013;63(2):561-569.

20. Jain R, Chaudhary D, Dhakar K, Pandey A. A consortium of fungal survivors after fire operations under shifting cultivation in Northeast Himalaya, India. Nat Acad Sci Lett. 2016;39(5):343-346.
21. Trivedi P, Pandey A, Palni LM. In vitro evaluation of antagonistic properties of Pseudomonas corrugata. Microbiol Res. 2008;163(3):329-336.

22.Nagarajkumar M, Bhaskaran R, Velazhahan R. Involvement of secondary metabolites and extracellular lytic enzymes produced by Pseudomonas fluorescens in inhibition of Rhizoctonia solani, the rice sheath blight pathogen. Microbiol Res. 2006;159(1):73-81.

23.Lim H, Kim Y, Kim S. Pseudomonas stutzeri YLP-1 genetic transformation and antifungal mechanism against Fusarium solani, an agent of plant root rot. Appl Environ Microbiol. 1991;57(2):510516.

24.Bollag DM, Rozycki MD, Edelstein SJ. Protein methods, 2nd Ed. Wiley New York. 1996:432.

25. Laemmli UK. Cleavage of structural proteins during the assembly of head of bacteriophage T4. Nature (London). 1970;277:680685

26. Trudel J, Asselin A. Detection of chitinase activity after polyacrylamide gel electrophoresis. Ann Biochem. 1989; 178(2):362-366.

27. Dietz A, Mathews J. Scanning Electron Microscopy of Selected Members of the Streptomyces hygroscopicus Group. Appl Microbiol. 1969;18(4):694-696.

28.Aghigni S, Boniar GHS, Rowashdeh R, Batayneh S, Saadoun L. First report on antifungal spectra of activity of Iranian actinomycetes strains against Alternaria solani, Alternaria alternata, Fusarium solani, Phytophthora megasperma, Verticillium dahlia and Saccharomyces cerevisiae. Asian J Plant Sci. 2004;3(4):463-471. doi: 10.3923/ajps.2004.463.471

29. Al-Askar AA, Abdul Khair WM, Rashad YM. In vitro antifungal activity of Streptomyces spororaveus RDS28 against some phytopathogenic fungi. Afr J Agric Res. 2011;6(12):2835-2842.

30. Muskhazli M, Ramli SA, Ithni A, Tohfah NF. Purification and characterisation of $\beta$-1, 3-giucanase from Trichodenna harzianum BIO 10671. Pertanika J Trop Agric Sci. 2005; 28(1): 23-31.

31.Gomes RC, Seme^do LTAS, Soares RMA, Alviano CS, Linhares LF, Coelho RR et al. Chitinolytic activity of actinomycetes from a cerrado soil and their potential in biocontrol. Lett Appl Microbiol. 2000; 30(2):146-150. 